\title{
CONCEPÇÕES E AÇÕES DE FORMADORES DE PROFESSORES DE QUÍMICA SOBRE O ESTÁGIO SUPERVISIONADO: PROPOSTAS BRASILEIRAS E PORTUGUESAS
}

\author{
Rejane Maria Ghisolfi da Silva* \\ Instituto de Química, Universidade Federal de Uberlândia, CP 593, 38400-902 Uberlândia -MG, Brasil \\ Roseli P. Schnetzler \\ Faculdade de Educação, Universidade Metodista de Piracicaba, Piracicaba - SP, Brasil
}

Recebido em 16/4/07; aceito em 4/4/08; publicado na web em 10/11/08

\begin{abstract}
LECTURERS' ACTIONS AND CONCEPTIONS ABOUT PRE-SERVICE TEACHING PRACTICES IN CHEMISTRY: BRAZILIAN AND PORTUGUESE PROPOSALS. The purpose of this paper is to investigate lecturers'actions and conceptions about pre-service teaching practices in chemistry. In this sense, it takes into account several theoretical references concerned with teacher education, which support the qualitative analysis of 18 interviews, gathered with 14 brazilian and 4 portuguese lecturers. Results reveal that the pre-service teaching practices in chemistry have been performed far from a technical approach, showing a paradigmatic rupture and presenting another logic related with teacher education in chemistry, which have improved the comprehension of the teachers' real practices, since these have been shaped by complex and unprescribed factors.
\end{abstract}

Keywords: pre-service teaching in chemistry; initial teacher education; lecturers' actions and conceptions.

\section{INTRODUÇÃO}

Atualmente, dispomos de inúmeros estudos e investigações que nos revelam que cursos de Licenciatura em Química/Ciências apresentam inúmeros problemas, já que não estão formando professores capazes de atuar adequadamente nas escolas de ensino fundamental e médio de nosso país. Apesar de Pereira ${ }^{1}$ constatar que "as licenciaturas permanecem, desde sua origem na década de 30, sem alterações significativas em seu modelo" (p.111), as comunidades estrangeira e brasileira de pesquisadores em ensino de Ciências/Química vêm investindo em diagnósticos sobre tais cursos e em propostas de melhoria, que estão contribuindo para mudar concepções tradicionais atribuídas à disciplina de Prática de Ensino de Química e Estágio Supervisionado. Assim, de uma perspectiva fundamentalmente marcada pela mera aplicação de modelos, procedimentos e/ou regras previamente aprendidos a situações práticas de ensino, típica do modelo de formação docente pautado na racionalidade técnica, ainda vigente na grande maioria dos nossos cursos de Licenciatura em Química, vários destes já incluem "nichos disciplinares”, pautados em um outro tipo de racionalidade: o da prática. E estes vêm se configurando como espaços de disciplinas de Didática, de Prática de Ensino de Química e Estágio Supervisionado. Nestes termos, vem se operando uma significativa mudança em cursos de Licenciatura em Química; uma mudança paradigmática, visando romper gradativamente com o modelo da racionalidade técnica. Isto vem implicando no desenvolvimento de práticas que o minem por dentro, significando catalisar mudanças no processo de formação docente, mesmo dentro de um contexto ainda marcado pelos ditames daquela racionalidade. Tais ditames e mudanças em práticas de formação docente no âmbito do Estágio Supervisionado constituem o foco central do presente artigo, principalmente ao considerarmos que a legislação atual estabelece $400 \mathrm{~h}$ de prática de ensino vivenciadas ao longo do curso de licenciatura em Química, acrescidas de 400 h de Estágio Supervisionado ao final do mesmo. O que fazer dessas e nessas tantas horas deve estar sendo o desafio enfrentado por muitos coordenadores

*e-mail:rmgsilva@ufu.br de cursos de Licenciatura em Química, ao mesmo tempo em que vários professores de Didática, de Prática de Ensino de Química e Estágio Supervisionado estão pensando: chegou a nossa hora! Mas, o que fazer? Como tornar essas $800 \mathrm{~h}$ realmente significativas para a formação docente inicial em Química, particularmente no âmbito dos Estágios Supervisionados? Estes têm sido considerados como um momento único de vivência escolar, onde se aprende a ensinar. Tal concepção vem orientando os estágios, potencializando a experiência prática como um dos momentos mais importantes do processo de constituição profissional docente. Desse modo, o estágio, na formação de professores foi, ou tem sido, um dos elementos mais valorizados em relação aos outros componentes do currículo formativo, principalmente pelos futuros professores. Entendendo que, embora ele seja um componente importante nos currículos formativos, não podemos considerá-lo como uma função à parte, nem como um apêndice do curso, como se houvesse lugares distintos para a teoria e a prática. Nesse sentido, a formação docente realiza-se por meio "de percursos diferenciados de acordo com as pessoas que dela são sujeito e objeto e os contextos em que ocorre"² (p.7). Tal percurso não é uma trajetória linear, mas evolutiva, contínua, com experiências partilhadas e com a construção de saberes necessários à profissionalização docente. Isto denota que o professor vai se constituindo com base em "quadros de referência sobre a profissão", que vão sendo construídos nas interações do futuro profissional com instituições escolares, com outros profissionais e com o próprio exercício docente "mas, sobretudo, com as oportunidades de estudo e reflexão sobre esse mesmo quadro de referências que lhe foi possível vivenciar desde o início de sua trajetória em direção à profissão"33 (p. 54). Nesse processo, os professores vão tecendo "maneiras de ser e estar na profissão" (p.16). Sem desconsiderar os diversos "loci" de formação, a área acadêmica exerce papel decisivo na constituição do futuro professor, pois é nela que "as experiências da vida se fazem experiência interior de formação e reconstrução da identidade pessoal"s (p.31). Importa, por isso, chamar a atenção para a unidade teoria- prática, visto que é na universidade que o futuro professor pode ter a oportunidade de articular o conhecimento teórico acadêmico, o contexto escolar e situações vividas no exercício da docência. 
De acordo com isso, defendemos a mudança nas práticas formativas, no sentido de que a formação docente seja situada em tempos-espaços pedagógicos em que saber e ação, teoria e prática, conjuguem-se de maneira indistinta, pois teoria e prática, apesar de suas especificidades, constituem-se mutuamente e assumem contornos singulares de tempo-espaços pedagógicos em que se realizam.

Especificidades e contornos singulares relacionados ao campo de estágio, no processo de formação inicial de professores, constituem o objeto do presente artigo. Tendo como pano de fundo a problemática da formação de professores, definimos e buscamos respostas às seguintes questões de investigação: quais são os saberes formativos envolvidos nos Estágios Supervisionados sobre ensino de Química? Quais concepções de Estágio subjazem às ações formativas dos formadores? Quais significados e sentidos são atribuídos pelos formadores àqueles Estágios? Como estes são por eles estruturados?

Partimos do pressuposto de que o Estágio Supervisionado se constitui em espaço privilegiado de interface da formação teórica com a vivência profissional. Tal interface teoria-prática compõe-se de uma interação constante entre o saber e o fazer, entre conhecimentos acadêmicos disciplinares e o enfrentamento de problemas decorrentes da vivência de situações próprias do cotidiano escolar.

Nesse sentido, esta investigação analisa dizeres de um grupo de formadores de professores de Química sobre suas atuações em Estágios Supervisionados, buscando indícios que configurem o percurso de suas ações e concepções sobre o ensinar a ensinar. Em outras palavras, buscamos promover uma recomposição e explicitação do capital experiencial daqueles formadores, contribuindo com referências para a reflexão sobre práticas de formação e análise destas, de forma a se fazerem conhecer além das aparências primeiras, ou dos limites de uma única experiência docente, de uma só instituição, de um só país. Por isso, foram envolvidos no processo investigativo formadores de professores de diferentes regiões do Brasil e do exterior.

Admitindo que, no Brasil, um dos "nós" da formação docente está na articulação teoria-prática, principalmente no que tange à relação desarticulada entre escolas e universidades, sentimos necessidade de buscar no exterior novos dados que pudessem se configurar como elementos teóricos, possibilitando, se pertinentes fossem, utilizá-los no sentido de melhorar tal articulação, ampliando nossa possibilidade de reflexão e análise. Optamos, então, por Portugal, por dois motivos: pela proximidade cultural e lingüística com o nosso país e por aquele país possuir modos de interações organizacionais e institucionais no Estágio Supervisionado diferenciados dos moldes atuais desenvolvidos no Brasil. A Universidade de Aveiro, em especial, possui espaços de reflexão e investigação sobre a problemática da formação de professores, o que pode configurar uma ação diferenciada dos formadores na formação de professores de Química. Tais espaços estão situados no curso de Mestrado em Supervisão e no Departamento de Didática e Tecnologia Educativa, que abriga, em seu interior, um Centro de Investigação de Didática e Tecnologia de Formação de Professores.

\section{APORTES TEÓRICO-METODOLÓGICOS}

A organização curricular da maioria dos cursos de Licenciatura em Química manifesta e enfatiza dois caminhos paralelos, que quase nunca se cruzam ao longo do curso, a não ser nas disciplinas de Prática de Ensino e Estágio Supervisionado. Isso significa que as disciplinas de conteúdo químico específico seguem seu curso independente e isolado das disciplinas pedagógicas e vice-versa. É, sobretudo, essa dicotomia ou falta de integração disciplinar que caracteriza o modelo usual de formação docente nos cursos de Licenciatura em Química, posto que usualmente são pautados na racionalidade técnica. Assim, com base nesse modelo, os currículos de formação profissional ten- dem a separar o mundo acadêmico do mundo da prática. Por isso, procuram propiciar um sólido conhecimento básico-teórico no início do curso, com a subseqüente introdução de disciplinas de ciências aplicadas desse conhecimento para, ao final, chegarem à prática profissional com os estágios usuais de final de curso.

No caso da formação docente, este modelo concebe e constrói o professor como técnico, pois entende a atividade profissional como essencialmente instrumental, dirigida para a solução de problemas mediante a aplicação de teorias e técnicas. ${ }^{6,7}$ No entanto, há aqui um sério condicionante que confere pouca efetividade a este tipo de formação: os problemas nela abordados são geralmente abstraídos das circunstâncias reais, constituindo-se em problemas ideais que não se aplicam às situações práticas, instaurando-se o distanciamento entre teoria e prática. ${ }^{8}$

Tal distanciamento manifesta-se tanto nas disciplinas de conteúdo químico quanto nas de conteúdo pedagógico. Nas primeiras, a discussão sobre o que, como e porque ensinar Química na escola média merece pouca ou nenhuma consideração. Esta reelaboração conceitual não tem lugar naquelas disciplinas, que são próprias para cursos de bacharelado, mas que ficam a dever quando situadas em um contexto de formação de futuros professores de Química porque não tratam de processos que promovam reelaborações do conhecimento químico em conhecimento químico escolar.

Por outro lado, a dicotomia teoria-prática também marca as disciplinas pedagógicas ofertadas pela Faculdade de Educação, as quais se caracterizam, geralmente, pelo tratamento de teorias e modelos pedagógicos dissociados do conteúdo químico que os futuros professores de Química deverão ministrar. Além disso, tratam de um aluno ideal, de um professor ideal, de uma escola ideal. E onde fica a escola real, o cotidiano escolar concreto, com suas situações complexas, às quais teorias e modelos ideais não se ajustam? $?^{9}$ Agregado a tal limitação, temos o agravante de que professores tendem a não utilizar métodos de ensino que lhes foram ensinados em Faculdades de Educação no decorrer de sua formação inicial, mas aqueles que foram usualmente utilizados na sua educação. ${ }^{10} \mathrm{Na}$ medida em que as disciplinas de conteúdos químicos específicos constituem a grande parte dos currículos da licenciatura e são geralmente embasadas no modelo psico-pedagógico da transmissão-recepção, reforçam a concepção ingênua de que ensinar é fácil: basta saber o conteúdo químico e usar algumas técnicas pedagógicas devidamente treinadas, preferencialmente, para serem aplicadas durante o período do Estágio Supervisionado em ensino de Química.

Concebidos como técnicos, os futuros professores de Química, ao final de seus cursos de Licenciatura, vêem-se desprovidos de conhecimento e de ações que lhes ajudem a dar conta da complexidade do ato pedagógico, ao qual não cabem receitas prontas nem soluções padrões, por não serem reproduzíveis e envolverem conflitos de valores. ${ }^{6,7}$ Além disso, a estrutura dos cursos de Licenciatura em Química parece não reduzir a influência e a força da formação ambiental, marcada por visões simplistas do ato de ensinar, construídas e reforçadas ao longo do processo de escolarização dos futuros professores. Assim, conforme Maldaner, ${ }^{11}$ há uma forte contradição naqueles cursos: o tão importante e usual objetivo de propiciar aos alunos um bom domínio de conteúdo químico não tem se concretizado, pelo menos em termos de formação inicial docente, já que os de formadores - professores universitários nos Cursos de Licenciatura - não vêem abordando discussões que dêem subsídios para que os futuros professores possam reelaborar conteúdos químicos em conteúdos escolares. Nesse sentido, a literatura revela que a tão óbvia necessidade docente de "conhecer ou dominar a base científica, o conteúdo a ser ensinado" ultrapassa em muito o que é habitualmente contemplado nas disciplinas científicas específicas, implicando conhecimentos profissionais relacionados à história e à filosofia das 
ciências, às orientações metodológicas empregadas na construção de conhecimento científico, às interações Ciência/Tecnologia/Sociedade e às limitações e perspectivas do desenvolvimento científico. Tais conhecimentos é que podem embasar um processo de ensino no qual o conteúdo químico não venha a ser abordado como pronto, verdadeiro, estático, inquestionável, neutro e descontextualizado social, histórica e culturalmente.

Todavia, são estas últimas concepções que caracterizam, usualmente, o tratamento dos conteúdos ministrados nas disciplinas de conteúdos químicos das nossas Instituições de Ensino Superior. São essas crenças do que seja conhecimento químico, carregadas de ranço empiricista-positivista e, conseqüentemente, da visão neutra de Química, da 'objetividade verdadeira' da observação científica que são enfatizadas junto aos futuros professores de Química. ${ }^{12}$

Em outras palavras, os professores dos Institutos ou Departamentos de Química vêm atribuindo às Faculdades de Educação a tarefa de formar professores, esquecendo-se ou ignorando que os conteúdos químicos que ministram precisam ser pedagogicamente transformados no curso da formação docente, disponibilizando-os para a promoção da aprendizagem dos futuros alunos de seus licenciandos quando, por sua vez, professores. Isso significa que o ensino de química implica a transformação do conhecimento químico em conhecimento escolar. Já que os licenciandos não poderão ensinar os conteúdos conforme os aprendem nas disciplinas químicas, com quem aprenderão sobre $o$ que, como e porque ensinar determinado conteúdo químico nas escolas média e fundamental?

Certamente não será com os profissionais das Faculdades de Educação, pois estes sabem outras coisas, mas não Química. À medida que não há espaço, tempo e nem interesse nas disciplinas químicas para reelaborações conceituais de conteúdos químicos para a escola básica, os licenciandos só podem aprender algumas dessas necessidades formativas com professores de Metodologia de Ensino de Química, Instrumentação para o Ensino de Química, Prática de Ensino em Química e Estágio Supervisionado. Caso contrário, tão logo se formem, acabam se tornando presas fáceis de livros didáticos de Química pouco adequados a um processo de ensino-aprendizagem significativo. ${ }^{9}$

No âmbito dessa problemática e desses desafios, podemos dimensionar a importância de novas proposições para a formação docente em Química, fundamentalmente cunhadas em pressupostos de uma outra racionalidade - a da prática - configurando outras concepções para as disciplinas acima referidas.

As orientações atuais enfatizam a idéia de formar o professor reflexivo, o professor pesquisador, defendendo a necessidade de a pesquisa educacional ser também realizada pelo professor que atua nos níveis de ensino fundamental e médio, tornando-se constitutiva das próprias atividades docentes, definindo-se como condição de desenvolvimento profissional do professor e de melhoria da sua prática pedagógica. ${ }^{6,13,14}$

Conceituando a reflexão como prática social, bem como destacando a importância da produção e divulgação de saberes docentes e teorias práticas usados e produzidos pelos professores, Zeichner e Liston ${ }^{15}$ explicitam cinco características básicas atribuídas ao professor reflexivo: examinam, esboçam hipóteses e tentam resolver os dilemas envolvidos em suas práticas de aula; estão alertas a respeito das questões e assumem os valores que levam/carregam para seu ensino; estão atentos para o contexto institucional e cultural no qual ensinam; tomam parte no desenvolvimento curricular e se envolvem efetivamente para a sua mudança e, assumem a responsabilidade por seu desenvolvimento profissional ${ }^{15}$ (p. 6).

A questão fundamental que abordamos neste trabalho é a de como os formadores de professores de Química, sujeitos desta investigação, tentam viabilizar a construção de tais características nos Estágios de Supervisão sob suas responsabilidades? A literatura nos indica a importância de levar em consideração a reflexão sobre a prática docente. Contrariamente ao que é enfatizado no modelo de formação docente pautado na racionalidade técnica, a prática docente é mais um processo de investigação do que um contexto de aplicação [de teorias e procedimentos]. Pérez-Gomes ${ }^{7}$ (p. 102) enfatiza tal idéia nos seguintes termos:

Parte-se da análise das práticas dos [futuros] professores quando enfrentam problemas complexos da vida escolar, para a compreensão do modo como utilizam e modificam rotinas, como experimentam hipóteses de trabalho, como utilizam técnicas e instrumentos conhecidos e como recriam estratégias e inventam procedimentos e recursos.

Enfatizando que ao refletir sobre sua própria prática o futuro professor de Química pode se converter em um investigador na sala de aula, produzindo saberes pedagógicos, as atuais recomendações de pesquisas sobre formação docente centram-se na temática de uma nova epistemologia da prática. Esta não desconsidera contribuições teóricas advindas da pesquisa acadêmica, produzidas nos moldes da racionalidade técnica, mas pressupõe a sua integração aos problemas da prática para possibilitar reflexões sobre ela, novos planejamentos, implementações, avaliações e novas reformulações, gerando saberes pedagógicos. Nesse sentido, Pérez Gómez ${ }^{7}$ (p.110) ressalta que:

...o conhecimento acadêmico, teórico, científico ou técnico, só pode ser considerado instrumento dos processos de reflexão se for integrado significativamente, não em parcelas isoladas da memória semântica, mas em esquemas de pensamento mais genéricos ativados pelo indivíduo quando interpreta sua prática. No modelo de formação de professores como artistas reflexivos, a prática adquire o papel central de todo o currículo, assumindo-se como o lugar de aprendizagem e de construção do pensamento prático do professor.

O que isso implica para os estágios supervisionados na formação inicial de professores de Química? Tal questão é que nos motivou a realizar a presente investigação.

\section{A INVESTIGAÇÃO: PROCEDIMENTOS METODOLÓGICOS}

A abordagem de investigação adotada é do tipo qualitativa, utilizando-se, como fonte principal de dados, entrevistas semiestruturadas, tendo como técnica o depoimento. Tal abordagem foi escolhida por permitir a compreensão dos modos como os formadores atuam em seus contextos profissionais e o sentido dado ao trabalho docente. Isto é, possibilita a explicitação das dimensões do vivido que influenciam nas decisões atuais e nas projeções de formas desejáveis de ação. Ademais, esse nível de estudo propicia a realização de orientações diferenciadas na abordagem do problema, pois, segundo Bogdan e Biklen, ${ }^{16}$ a abordagem qualitativa assume muitas formas e é conduzida em múltiplos contextos.

Desse modo, foram entrevistados 14 formadores brasileiros e 4 portugueses que atuavam ou atuam como orientadores de Estágio nos cursos de Licenciatura em Química, sendo que o grupo português inclui um professor universitário (S.Pt) e três professores do ensino secundário (T.Pt, V.Pt, U.Pt), que atuam ou atuavam como supervisores de Estágio. Todos os 18 sujeitos desta investigação têm formação acadêmica de alto nível, com efetiva atuação na área de educação química. Como aconselha Queiroz ${ }^{17}$ (p. 102), "é preciso escolher informantes válidos”, isto é, "aqueles que se supõe de antemão 
possuir uma vivência do que se procura conhecer". Nas entrevistas, foram solicitadas: razões para a escolha profissional, sua formação, seu percurso profissional e suas ações (o que fazem e como o fazem), dificuldades sentidas, expectativas, o que funciona bem e o que não funciona nos Estágios Supervisionados sobre ensino de Química. Tais depoimentos foram gravados em áudio e, posteriormente, transcritos. Cada entrevistado é designado por uma letra do alfabeto, acompanhada de $\mathrm{Br}$ (Brasil) ou Pt (Portugal). Tal procedimento foi necessário para se assegurar o anonimato dos entrevistados.

Na construção e análise dos dados, o caráter qualitativo foi dado pelo fato de a ênfase recair na captação de significados, nas definições da situação e nos pontos de vista dos sujeitos envolvidos. ${ }^{18}$

\section{CONTEXTOS INVESTIGATIVOS}

Em Portugal, os estágios estão organizados em "núcleos” e visam o desenvolvimento pessoal e profissional dos estagiários. Tais núcleos compreendem pequenos grupos de alunos universitários, distribuídos em escolas da rede pública articuladas à universidade, orientados por um docente da escola e por um ou dois docentes da universidade. Os objetivos dos núcleos de ensino são voltados para o desenvolvimento, em situação de formação cooperativa, do conhecimento profissional necessário ao exercício da prática docente responsável e da reflexão crítica sobre ela, para a mobilização integrada de saberes adquiridos nos diferentes componentes da formação inicial do aluno estagiário e para a sua integração progressiva e orientada no exercício da atividade docente na comunidade escolar.

As escolas, núcleos de Estágio em ensino, contam com uma boa estrutura de apoio, pois possuem biblioteca, laboratórios de ensino de Química amplos e equipados, computadores, data show e acesso à Internet. Tais núcleos são organizados em tempos específicos para atividades de planejamento, execução, supervisão e análise-avaliação dos Estágios de ensino. Cada estagiário, na escola, ministra aulas para uma turma regular e, ainda, pode partilhar uma turma com o professororientador, na condição de professor contratado.

O Estágio pedagógico acontece ao longo de 1 ano letivo completo, quando o licenciando tem a possibilidade de se familiarizar com normas, valores e cultura, inerentes à profissão docente. Os alunos estagiários envolvem-se com diferentes atividades na escola: regência de classe, organização e/ou participação em trabalhos extracurriculares, projetos interdisciplinares, reuniões e/ou contatos com os pais, entre outras, e com responsabilidades de natureza diversa, com desafios e níveis de exigência que os levam a assumir uma profissionalidade docente. Tais atividades e responsabilidades são referidas por alguns autores como promotoras de desenvolvimento nos futuros professores. ${ }^{19-22}$

Os docentes do ensino básico ou secundário, na função de supervisores de Estágios, desempenham várias tarefas, tais como organizam a distribuição das turmas para cada estagiário; prestam assessoria pedagógica à prática docente dos estagiários mediante reuniões, seminários, assistência e análise crítica das aulas; participam de atividades de formação organizadas pela universidade; promovem a integração do estagiário na escola e na comunidade; avaliam e classificam os estagiários em colaboração com os docentes da universidade.

Já aos docentes universitários, orientadores de núcleo de Estágio, cabem, genericamente, orientar cientificamente os Estágios sob sua responsabilidade, tendo em vista um plano coordenador dos trabalhos a serem realizados; reunir-se periodicamente com os professores do ensino secundário e alunos estagiários do seu núcleo, de acordo com as atividades programadas pela respectiva comissão de Estágio; dedicar-se aos trabalhos de orientação de Estágios o período de tempo que vier a ser definido pelo regulamento, não podendo ser, em qualquer caso, inferior a $2 \mathrm{~h}$ semanais. O número de estagiários por núcleo é, em média, de 4 alunos.
No Brasil, é prática usual o aluno matricular-se na disciplina de Prática de Ensino e ser encaminhado para uma escola de ensino básico. O Estágio corresponde, usualmente, a 1 semestre letivo. O licenciando vai até a escola, dá as suas aulas e não participa integralmente das atividades cotidianas, por cumprir, ainda, disciplinas necessárias à conclusão do curso. $\mathrm{O}$ docente da escola auxilia na condução das atividades escolares sem se comprometer com a formação do futuro professor. $\mathrm{O}$ calendário escolar não coincide com o calendário da universidade. Deste modo, a imersão do licenciando no contexto escolar se dá em período posterior ao início das aulas. A forma como estão estruturados os Estágios no Brasil recebe inúmeras críticas, que são, "basicamente, comuns às Instituições formadoras, sejam elas públicas ou privadas". ${ }^{23}$ Segundo Goulart, ${ }^{23}$ uma das críticas se refere à artificialidade da situação na qual se realiza a prática. Outras apontam falhas em termos do acompanhamento de Estágio, o curto período da disciplina de Prática de Ensino e as poucas oportunidades que o estagiário tem para lecionar.

\section{ANÁLISE E DISCUSSÃO DOS RESULTADOS}

\section{Práticas de Ensino de formadores brasileiros}

Ao analisar os depoimentos dos formadores brasileiros foi possível identificar que eles assumem a perspectiva do modelo da racionalidade prática e a crítica ao modelo da racionalidade técnica.

o maior problema na formação docente é o modelo. Esse modelo voltado para a racionalidade técnica, esse descrédito, essa desconsideração de alguns formadores com a formação de professores, principalmente daqueles do campo das disciplinas de conhecimento específico (...) Como é que a gente pode mudar? Nós vamos ficar esperando que um outro modelo caia por si? Não! Esse é o nosso desafio aproveitar ao máximo o tempo das nossas disciplinas de Prática de Ensino (H.Br).

A prática de ensino não é só mandar os alunos fazer plano de ensino e olhar os planos, assistir aulas e terminou aí (A.Br).

Os formadores deixam transparecer, pelos depoimentos transcritos, a proposta de formar professores reflexivos/pesquisadores, o que implica em explicitar, desconstruir e reconstruir concepções dos futuros professores sobre o ensinar Química. Nesse sentido, assumem o que mais caracteriza o pensamento reflexivo, ou seja, a postura de questionamento, de problematização, ao provocarem reflexões em seus alunos sobre as práticas de ensino que planejam e desenvolvem nas escolas.

A pérola da disciplina é o estágio. $O$ aluno intervir, refletir sobre o que fez e depois voltar a ter oportunidade de agir novamente. São os ciclos. E você vendo a evolução do aluno e lidando com problemas práticos. (I.Br)

Eu não me sinto tranqüilo em formar, em trabalhar com a formação apenas de alguém que vai trabalhar, apenas dar aulas de química e tem que ter preocupações com os conteúdos apenas e com as formas que vai transmitir. (G.Br)

Eles vão a escola, percebem determinadas coisas, atuam como professor, e retornam à universidade. Trazem questionamentos ao mesmo tempo em que são apresentados novos aportes, novos referenciais para que possam ver a situação de 
modo diferente e poderem retornar à escola com uma outra visão, buscando outras coisas e aí construir novas coisas e retornar novamente à universidade e de novo ter a chance de refletir e discutir a prática realizada. (G.Br)

O professor é um prático reflexivo. E nossa disciplina tem um espaço privilegiado, pois todos os problemas discutidos nas outras disciplinas deságuam na Prática de Ensino, por exemplo, a questão conceitual, às vezes, os alunos têm um conhecimento avançado, mas, muitas vezes não têm clareza sobre certos conceitos básicos. (I.Br)

Alguns formadores discutem propostas e recursos didáticos para o ensino médio de Química, possibilitando aos estagiários o conhecimento de organizações conceituais relacionadas a temas da vivência dos alunos. Desse modo, ensinam e auxiliam seus estagiários a planejar, desenvolver e analisar aulas de Química.

Discutimos o planejamento das aulas. - Ah, vou dar aula sobre ligação química? Bem, então, como é que você planejou a aula? Por que você fez desse jeito? Que fatores você considerou? Então ele vai lá e aplica a aula. - Agora, diz para nós o que aconteceu? Como foi o desempenho dos alunos? $O$ que você achou? Se foi bem, ao que você atribui? Não saiu bem, ao que você atribui não ter saído bem? Vamos ver quais variáveis você acha que estão interferindo? (M.Br)

Então, vão dar aula de quê? Ah! Vamos dar aula sobre metais! Está bom! Então, quais questões vocês vão fazer para os alunos para saber as idéias que eles têm sobre metais? Aí, iam lá pensar nas questões. 'Vamos ler a literatura?' Dava lá os artigos que tratavam disso. 'Como é que vocês vão levar em conta essas idéias, dada a grande possibilidade das idéias dos alunos serem essas ou muito semelhantes a essas?' 'Como é que vocês vão fazer?' 'Que tipos de discussão, sobre a importância dos metais vocês vão tratar com os alunos?' 'Quais conceitos vão tratar?' Ou seja, a gente começa a pegar essas coisas dentro da perspectiva deles prepararem a aula e darem a aula, e é isso que para eles é importante. Eles querem logo cair na prática. (D.Br)

Os formadores procuram contemplar certas necessidades formativas, em particular, a problemática da reelaboração pedagógica de conceitos químicos, o desconhecimento sobre a complexidade da prática docente, as visões empiricistas e positivistas de Ciência/Química e a separação entre conhecimentos químicos e a vida cotidiana.

Como eles estudaram as concepções dos estudantes, eu proponho a eles, por exemplo, investigar qual é a concepção dos seus alunos sobre o tema em estudo. Aí eles buscam conhecer as concepções e trazem para a sala de aula para discussão. (M.Br)

Em termos de suas ações formativas, os formadores brasileiros discutem concepções do processo de ensino-aprendizagem em Química (transmissão-recepção ou ensino tradicional e abordagens construtivistas e histórico-cultural), abordam concepções prévias de alunos sobre conceitos químicos importantes e discutem estratégias de ensino que as levem em conta.

Nós discutimos modalidades de ensino. Lemos como é uma aula expositiva. E questionamos: Como é a tua aula expositiva? Em que este texto te ajudou na tua sala de aula? Fala como é a tua sala. Então, cada um conta como é a sua aula, como eles dão aula, como eles planejam. Discutimos sobre o papel do experimento, sobre as concepções de ensino e aprendizagem em química. (M.Br)

Os formadores também procuram enfatizar a negociação de significados em sala de aula e a articulação de saberes dos alunos com saberes químicos. E o fazem abordando conceitos químicos fundamentais e discutindo critérios epistemológicos e teóricometodológicos relativos ao que, como e porque ensiná-los na escola básica, exemplificando como abordá-los.

Proponho aos futuros professores que analisem os conceitos dos programas das escolas e proponham uma forma alternativa de programa. Depois comparem com a proposta alternativa de ensino e reescrevam as situações de estudo. (B.Br)

Procuram destacar as interrelações dos níveis fenomenológico, teórico-conceitual e representacional do conhecimento químico, exemplificando modos de articulação para conceitos químicos fundamentais, como transformações químicas e substância.

Eles planejam uma aula e a gente discute se é possível fazer uma atividade prática ou não. É possivel? Ah! É. Não é. Então vamos discutir o que vocês acham que poderia ser feito. (M.Br)

Discutem a linguagem química como constitutiva do pensamento químico, que se configura como capacidade de interpretar, explicar e prever fenômenos químicos, exemplificando com reelaborações pedagógicas de conceitos químicos adequadas ao ensino médio de química. Criticam visões empiricistas e positivistas de Química e abordam a experimentação como problematização e exploração de tentativas de explicações e interpretações por parte dos alunos, promovendo discussões conceituais que favorecem a construção de conhecimentos.

Eu gosto de mostrar a eles que na experimentação o mais importante é motivar a discussão, a interpretação daquele fenômeno que ali está. Isso nunca fizeram com ele pois eles estão submetidos a roteiros, que ou dá certo ou dá errado. Nesse caso a gente procura romper com este esquema, dar uma outra visão sobre o erro, a certeza, a verdade. Trabalhar com possibilidades, hipóteses, mostrar para eles que a coisa mais importante é de fato fazer o aluno pensar, planejar experiências que poderiam ser feitas. Procuro marcar muito a importância da interpretação dos fenômenos através da articulação entre os níveis teórico conceitual e fenomenológico. $(\mathrm{H} . \mathrm{Br})$

Além disso, os formadores promovem interações de seus alunos com modos de ação docente no ensino médio de Química que possibilitam reflexões sobre práticas de profissionais experientes, sobre a realidade das salas de aula através de observações de aulas e de vídeos de aulas, seguidas de análise; entrevistas com alunos e professores de química e, pela participação de professores experientes nas reuniões/aulas sobre o Estágio Supervisionado. Quanto a este, orientam, acompanham e supervisionam as aulas dadas por seus estagiários, as quais são geralmente filmadas e discutidas, provocando em seus alunos reflexões sobre as mesmas através de questões do tipo: o que deu certo? Por que? O que não foi bem? Por que? Como melhorar a aula? O que está levando em conta para preparar a aula? 
O que é observar uma sala de aula? O que eu vejo na sala de aula? Os padrões de interações discursivas, as dinâmicas diferenciadas, as estratégias que são usadas, as questões do relacionamento afetivo, emocional, a questão da disciplina? Quer dizer, é uma série de coisas. A sala de aula é um espaço complexo, então não tem jeito de você caracterizá-la sem levar em conta tal complexidade. É nesse sentido a tentativa do curso de mostrar essa diversidade prática e mostrar que algumas são mais diversas que outras, ou seja, há professor cuja prática é muito limitada em termos de estratégias ou coisas que ele usa que a gente conhece. (I.Br)

Os alunos vão dando aula e vamos filmando. Em seguida analisamos a aula com os alunos e tecemos comentários. Os alunos voltam a dar aula e dá para perceber a evolução do aluno. (I.Br)

Nas observações que propomos numa primeira visita eles vão levantar aspectos mais gerais da escola. São conduzidos a pensar a escola como um projeto político, ou seja, a relação dela com a comunidade, a questão da organização do trabalho da escola. Isso para mudar a concepção de escola isolada para escola como um projeto coletivo. Eles acompanham o professor de química, vê o aspecto da formação dele, da organização do trabalho, da autonomia que ele tem e passam a observar suas aulas. Ao mesmo tempo introduzimos uma leitura teórica: o que é observar uma sala de aula? O que eu vejo na sala de aula? Quais os padrões de interações discursivas? Há dinâmicas diferenciadas? Quais estratégias são usadas? Como é o relacionamento afetivo, emocional? Como é a disciplina? (I.Br)

Os formadores propõem que os estagiários analisem propostas, desenvolvam e avaliem projetos/unidades de ensino escolares, explorando aspectos epistemológicos, metodológicos e pedagógicos.

Os tutoramentos estão sendo realizados no diálogo com a realidade escolar, utilizando a pesquisa para a busca do conhecimento e da compreensão da realidade, bem como sua problematização. (...) Propõe-se o conhecimento das concepções epistemológicas, metodológicas e pedagógicas das escolas envolvidas, contribuindo para a tomada da consciência dos futuros professores sobre essas concepções. (F.Br)

Preocupações no sentido de que o estágio pedagógico não se restrinja a um único momento formativo orientam propostas e ações formativas, de modo a consolidar o diálogo entre prática e teoria ao longo do curso.

Cada tutoramento tem um objetivo específico. O primeiro propõe um reconhecimento da escola e da sala de aula. $O$ segundo e o terceiro enfocam estudo das questões experimentais no ensino e o quarto, a partir de todo o conhecimento e experiência adquiridos por eles, eles propõem um projeto de ensino, com preparação de materiais para serem aplicados no estágio supervisionado. (F.Br)

Nesse sentido, os formadores procuram sinalizar com práticas diferenciadas e com experiências de campo diversificadas para os futuros professores, na perspectiva de dar referências de práticas de ensino.
Eu acredito na imitação, penso que Schön está muito certo em algumas coisas. Se o formador não marcar certas coisas com os alunos, fica muito difícil, por isso que é muito natural eles, às vezes, falarem: - 'Ah, professora, por que a senhora não dá uma aula construtivista de ácidos e bases para a gente ver como é? Não é na perspectiva da cópia, da receita, mas é na perspectiva de você marcar certas ações que são consideradas importantes na docência. (D.Br)

Eu hoje faço um curso que tem muito a ver com essa preocupação de dar ao aluno uma condição de vivenciar uma prática alternativa, ou seja, não tenho interesse que esse aluno vá vivenciar uma prática tradicional que ele já vivencia com a formação ambiental que ele vem recebendo. É claro que, para isso, é fundamental essa articulação que a gente tem da formação continuada com a formação inicial, ou seja, nós temos professores que podem receber os estagiários e que são professores que têm uma prática diferenciada e também a questão da existência do colégio técnico e do centro pedagógico, onde a gente faz muito estágio. Então, esse estágio não é um estágio qualquer, a gente faz primeiro toda essa questão de ter uma prática alternativa, ter o acompanhamento desses alunos, filmar essas aulas, usar esses vídeos para depois analisar e fazer uma reflexão. (...) é um trabalho que pelo menos possibilita ao aluno uma referência de como fazer um ensino de uma maneira diferente, porque eu acho que não adianta nada a gente aqui na universidade, se a universidade não intervém no sistema no sentido de mudança. (I.Br)

Os formadores acreditam que a prática seja fundamental, todavia assinalam que ir direto para as práticas é contribuir para manter o ensino tradicional, pois argumentam que faltará o embasamento teórico que dê suporte a essa prática.

Venho consolidando a idéia de que a ação do aluno, a prática na organização do espaço da aula é imprescindivel para a sua formação, desde que caminhando junto com a interlocução teórica e com a reflexão para a tomada de consciência do que está fazendo e dos seus resultados. (F.Br)

As práticas de ensino também são pensadas conforme a disponibilidade do aluno, da experiência de cada um como professor. Exemplo disso são as ações pensadas para o curso diurno, que diferem das do curso noturno. No curso diurno o número de horas é maior, sendo assim, há mais tempo para a realização de intensas discussões de textos teóricos, questionamentos de idéias de "senso comum" sobre ensino e aprendizagem de Ciências, análise crítica do ensino tradicional e preparação de atividades geradoras de aprendizagens significativas e, ao final, os alunos mergulham na prática. No noturno o tempo é menor, portanto, não convém ir logo para a prática, pois "é praticamente criar uma situação de reforçamento do modelo de transmissão e recepção, os alunos estão ainda acreditando naquilo”. (D.Br)

Então, por isso que eu acho que a melhoria também da formação não é colocar a prática logo no início. O sujeito precisa ter no início um período em que você problematize com ele sobre as grandes questões do ensino de química e dando acesso a algumas contribuições teóricas. (C.Br)

Independentemente do contexto de formação, é indiscutível a necessidade de uma sólida formação teórica, sem menosprezar a prática. Deve-se, entretanto, ter o cuidado de não cair no culto da teoria pela teoria, mas que, pela teoria, se pense a prática de forma 
rigorosa e profunda e vice-versa.

A análise dos depoimentos dos formadores brasileiros permite inferir que, de modo geral, privilegiam estratégias de discussões/ diálogos como momentos de reflexão e (re)construção do ato pedagógico nas situações de estágio. É na conjugação das atividades com o exercício da reflexão que o pensamento se faz e busca perfazer-se para, por meio da ação, gerar novos conceitos e princípios orientadores de futuras ações, que se constituem estruturadoras do pensamento. No delineamento dos processos formativos, há a perspectiva de uma formação mais participativa que permite dar voz ao pensamento dos licenciandos e à abertura para inovações no contexto de sala de aula.

Uma outra evidência importante relaciona-se à busca de múltiplas possibilidades de construção de saberes necessários à docência. Para isso, são possibilitadas inúmeras situações em que os licenciandos interagem com alunos de diferentes realidades, com profissionais mais experientes, com tempo e espaço múltiplos.

\section{Práticas de Ensino de formadores portugueses}

As disciplinas de Prática de Ensino sempre foram identificadas como disciplinas de segunda categoria, a concepção de que ensinar é uma tarefa fácil, que basta saber o conteúdo e algumas técnicas, fazem prevalecer a postura arraigada na qual não se assume a formação de professores por igual entre os formadores. Os formadores das áreas específicas não se apropriam dos cursos que ministram, direcionandoos fundamentalmente aos bacharelados. Sem o enfrentamento dos problemas no contexto de atuação na universidade e das questões políticas e estruturais não há como ter avanços significativos no âmbito da formação docente.

Olham os estágios de esguelha, porque isso é ocupação de tempo para os cientistas" (...) a maior parte deles (professores da área científica) acha que é um frete, uma massada enorme ter que ir na escola. Ainda por cima porque é mal pago na educação, não se ganha nada para ir lá, o trabalho não é contabilizado. A deslocação é paga como se fosse transporte público, quer dizer, se a pessoa for no seu próprio carro nem seguro tem. (P.Pt)

No tocante às ações dos formadores, são realizados os ciclos de supervisão, os quais incluem assistência a aulas e análise destas. Reúnem-se periodicamente com os orientadores das escolas do ensino básico e/ou secundário e com os alunos do seu núcleo, com a finalidade de acompanhar e coordenar o processo de formação, além de programarem sessões de trabalho de caráter científico e/ou pedagógico-didático, orientadas para a resolução de situações educacionais. Além disso, avaliam os alunos em colaboração com os orientadores da escola.

"S.Pt" relata que deixa seus alunos muito à vontade em relação ao modo como vão conduzir a aula, desde que haja coerência no todo. Em sua fala, acentua a importância do futuro professor ter um bom conhecimento da matéria a ser ensinada. "Não digam asneiras". Esta frase é contemplada em diversos momentos no relato da formadora e revela a sua preocupação com a construção do conhecimento químico. Ela não admite que os alunos estagiários possam cometer erros conceituais.

Se vocês se sentem confortáveis a dar uma aula expositiva do princípio ao fim, tudo bem, mas não digam asneiras. Se for a única maneira que vocês se sentem confortáveis para dar aula, dêem aula assim. Se vocês conseguem uns graus de liberdade, fazer interação com os alunos e fazer perguntas $e$ ouvir as respostas deles, e se os alunos disserem uma resposta errada, vocês terão que saber que a resposta é errada.(...) Eu prezo profundamente que não saiam com asneiras nas aulas. Nós podemos ser construtivistas ou ser o que quisermos, mas nada disso funciona diante de uma sala de aula se o docente disser asneiras. (S.Pt)

A questão é a seguinte: eu analiso a aula dos estagiários, que pode ser a seguir, ou dias depois. Em geral, eu analiso na escola. Eu, neste momento, minha metodologia foi mudada. Antigamente, eu estava a assistir à aula, se o aluno me dizia asneira, eu anotava as asneiras e sentava no final da aula e dizia: 'Você vai ter que corrigir isso e isso.' Agora decidi que é melhor intervir na aula. Desculpe dizer isso. Outro dia alguém dizia: 'Ah! $O$ aluno daí não tem respeito pelo professor em sala'. Mas o professor também tem que saber dar-se o respeito. E o professor que diz asneiras na sala de aula não está respeitando ninguém. Os alunos não são burros e podem chegar a casa e dizer que o professor ensina tudo errado, e o orientador estava lá atrás e não disse nada. Por isso, neste momento, é assim: Se há asneira do tipo um sinal trocado, eu digo: 'Olha o sinal está trocado'(S.Pt).

S.Pt citou alguns temas que são discutidos nas situações de orientação, são eles: postura do professor frente aos seus alunos na sala de aula, significado de ter autoridade e de ser autoritário, relação professor-aluno, clima/atmosfera de sala de aula e linguagem como comunicação.

Ela revelou, em seu depoimento, uma preocupação com os aspectos relacionais/humanos, professor-aluno. "S.Pt" mencionou que o professor não pode desconhecer o lado pessoal dos seus alunos e acrescenta que, às vezes, uma palavra, um gesto podem motivar os alunos nas aprendizagens escolares.

Desse modo, a concepção de sala de aula da formadora configurase como espaço físico, cultural e relacional. ${ }^{5}$ Assim, não é apenas espaço de comunicações verbais, mas espaço no qual estão interpenetrados o mundo físico e social. ${ }^{5}$

Professor tem que ser capaz de, quando vê um aluno angustiado, perceber porque ele está angustiado e não deixá-lo sair angustiado da sala de aula. (S.Pt)

Nesse sentido, Paulo Freire, ${ }^{24}$ quando analisa os saberes fundamentais à prática educativa, alerta que ensinar é uma especificidade humana. Portanto, nesse contexto, gestos, palavras, olhares, escutas atenciosas, diálogos carregados de significados, podem favorecer o processo educativo.

Exemplo disso está na situação apresentada a seguir, narrada por S.Pt. O aluno tinha notas baixas e estava muito desanimado. 'Oh! Professora, não vale a pena estudar!' E ela, sentindo que este aluno precisava de um estímulo, passou-lhe as mãos nas costas e falou-lhe sobre o tempo que deveria dedicar-se à disciplina e sobre como estudar. Passados alguns dias, o aluno veio ter com ela muito animado, falando-lhe que tinha gostado e estudado mais a disciplina.

Que mensagem o professor enuncia ao passar a mão nas costas dos alunos? E que mensagem o aluno capta desse gesto? Para a formadora, este é um tema para ser discutido com seus alunos estagiários.

Eu acho que a universidade é um sítio muito asséptico no sentido de que está desconhecendo os problemas que os alunos trazem. (S.Pt)

Nas relações sociais de sala de aula, são explicitados limites, distâncias, processos de aproximação e de afastamento, em que 
posturas corporais, atitudes e comportamentos estão em interconexão com os processos educativos. Nesse sentido, entende-se o porquê da preocupação da formadora "U.Pt", quando fala que o estagiário deve cuidar da sua postura, das formas de agir na sala de aula:

O estagiário desaparece na aula. Chega ao pé do aluno, põe-se de cócoras a falar com o aluno e eu de repente olho e digo: 'Onde está o estagiário? (U.Pt)

Os valores são outro aspecto para o qual a formadora chamou a atenção. Para ela uma das coisas que se perdeu em Portugal foi o valor da autoridade. Segundo ela falar em autoridade não é ser autoritário. Desse modo, o professor têm poder para tomar certas atitudes, assim como os seus alunos têm poder para outras coisas. Todavia eles têm de saber como usá-lo.

É fundamental fazer essa distinção, pois ela dá origem a papéis e estruturas distintas, que permitem compreender melhor o comportamento e atitudes estratégicas do formador no contexto interativo de sala de aula. Os atos interativos podem proporcionar, no seu interior, diferentes atos pedagógicos, de abertura ou de fechamento, de negociação ou de simples transmissão. Ser autoridade não significa centrar o discurso somente em si. Mas é fazer do discurso um processo interativo, uma construção colaborativa.

Quando a professora se referiu ao clima da sala de aula, destacou a importância de ter movimento, ou seja, "barulho" na sala de aula. Contudo alertou:

Quando vocês vêm dizer que a aula tem muito barulho, então vamos analisar que barulho é esse. (S.Pt)

Todas as situações vividas por ela são lições exploradas com seus alunos. Assim, por exemplo, tendo ministrado aulas para filhos de pescadores, discutiu com seus alunos a importância do domínio das relações intersubjetivas e do reconhecimento da distância cultural na comunicação didática.

Eu perdi aquela turma porque eram todos filhos de pescadores e eles nem sequer entendiam o que eu dizia. Só no meio do ano é que eu percebi que havia ali um hiato de comunicação que era lingüístico. Como eu não estava habituada com as comunidades pescatórias, acontece que os meninos filhos de pescadores ficaram todos na mesma turma, e acontece que o problema da falta de sucesso das crianças (debatíamos isso no estágio) era que de fato eu não tinha linguagem para meninos filhos de pescadores. Só muito tarde fui ver que era um problema de comunicação. O meu vocabulário não servia, eles tentavam falar o meu. Somente muito tarde percebi que tinha perdido a turma. (S.Pt)

Por meio da reflexão sobre a prática vivida, a formadora busca (re)construir os conhecimentos, ao mesmo tempo em que orienta a ação dos futuros professores. Desse modo, tais orientações não se configura de forma mecanicista e automática. A natureza das interações pode ser facilitadora ou inibidora de aprendizagens e do desenvolvimento do futuro professor. Nesse sentido, gerar situações didáticas das quais emergem novos sentidos e novas aprendizagens constitui uma relevante estratégia formativa.

A formadora "T.Pt" descreveu suas ações de supervisora, enfatizando as interações com os estagiários. Deixou claro que o seu papel não se restringia a observar e criticar as aulas por eles dadas, pois, nesse processo, é colaboradora e investigadora. Realizou reflexões sobre as práticas, seminários, no sentido de melhorar sempre as estratégias e todo o desenvolvimento da aula. Solicitava aos alunos uma reflexão por escrito que constava no seu dossiê (plano de curso, plano de unidade, planos de aula, xerox do caderno de chamada e reflexão sobre o dia-a-dia). Nos seminários, eram realizados os planejamentos e elaboradas as fichas de testes, reflexões sobre as aulas e autocríticas.

"V.Pt" relatou que, inicialmente, apresenta a escola ao grupo de estagiários, explicando sua organização, funcionamento, regulamento interno, corpo docente, espaço físico, laboratório de Física e Química. Depois distribui as turmas, analisa o programa da escola com os alunos, fala sobre a avaliação e dá início às orientações para a realização dos planejamentos (plano anual, plano de unidades, plano de aulas). Os planejamentos são realizados em conjunto, mas, aos poucos, o formador vai dando maior liberdade na elaboração dos planos. Discute temáticas como (in)disciplina na sala de aula.

Esta é uma temática pouco explorada pelos formadores de professores: a natureza dos alunos no ensino secundário (médio) e a dificuldade do professor para "lidar com eles". S.Pt", também, se refere a este aspecto quando relata sua experiência docente em escola de periferia.

Portugal é uma mistura explosiva que é extremamente difícil, pois é diferente a maneira de pensar, de ver, de estar na vida, é completamente diferente. E obviamente isto vai para a escola, pois as escolas não são sítios idílicos e nem parasidíacos. (S.Pt)

Sabe-se que as relações de sala de aula são complexas. Ninguém deixa suspenso à porta da sala de aula o seu jeito de ser. No entanto, da atmosfera estabelecida na sala de aula, das interações significativas do grupo, dependem as condições do processo das aprendizagens mediadas pela docência. A hipótese é de que as tensões possam ser superadas pela flexibilização curricular, pela qual é possível a articulação do mundo da vida e do mundo do conhecimento científico e tecnológico.

Outra postura adotada pelo formador "V.Pt" era questionar seus alunos sobre o que eles esperavam dele como supervisor. Realizava seminários com abordagens relacionadas aos planejamentos, construção de materiais didáticos, discussão e análise das aulas, estruturação de estratégias, preparação e organização de exposições. Propunha pesquisas na Internet para apoio ao processo de ensino e aprendizagem.

Algumas das ações do formador "U.Pt" coincidiam com os modos de agir dos outros formadores. Relatou que uma das primeiras tarefas é realizar o "enquadramento", que seria a inserção do aluno no contexto escolar. Isto acontecia, segundo o formador, em vários níveis: pessoal, legal e didático-pedagógico. Havia uma preocupação com os aspectos relacionais, como interações professor-aluno. Realizava seminários, assessorava planejamentos dos estagiários, observava aulas e fazia uma análise reflexiva posterior. Na parte final do estágio, intervinha de maneira mais pontual, específica. Portanto, havia dois momentos: uma parte coletiva, na qual os alunos colocam suas dificuldades, e outra individual.

Demonstra, também, pelo seu depoimento, uma preocupação com o trabalho prático, com a abordagem em contextos de natureza social, tecnológica e, muitas vezes, ambiental. E essa preocupação era a temática dos seminários. Fazia intervenções específicas nesse campo, apresentando temas tais como: perspectiva CTS (Ciência, Tecnologia e Sociedade), concepções alternativas, trabalho prático, resolução de problemas, abordando-os com sugestões e contraposições às intervenções específicas que observava na sala de aula.

$\mathrm{O}$ formador deixou transparecer, pelas suas palavras, que privilegiava ações para que os alunos estagiários adquirissem uma certa autonomia. Isso é evidente pela prática narrada. 
Eu desenvolvo um trabalho coletivo, o trabalho de grupo, $e$ outro individual, o estagiário comigo. Mas podem solicitar ajuda sempre que o pretenderem. Procuro que eles coloquem os problemas entre eles. Sou um adepto de que inicialmente mostrem os planos de aula, mas, com o tempo, eles têm que assumir aquilo como projeto deles, porque se nós começarmos a corrigir todo o plano, o estagiário iria dar a nossa aula. Para isso, mais valia dar-lhe um plano de aula já feito. Há probabilidade de haver erro, o que é natural, desde que não seja um erro catastrófico, pois se aprende com os erros. Se tem em mente algum processo que pode não ter o melhor sucesso do meu ponto de vista, mas é algo proposto por ele, reflectido, não levanto obstáculos a que realize esse projecto. Depois fazemos uma análise crítica da aula e conversamos, discutimos outras possibilidades, outras opções e ele mudará, ou não. Eles próprios vão sentir necessidade de procurar outros aspectos, outras metodologias ou estratégias. Depois, na discussão, apresento novos problemas: 'Por que fez assim? o que poderia acontecer se não fizesse assim?'O efeito reflexivo é aquele que mais me interessa, saber a consistência do que está a fazer ou já fez. Não só as estratégias em si mesmas, mas as razões subjacentes às mesmas. (U.Pt)

A reflexão sobre as ações é, por conseguinte, um meio para a conquista e/ou para o desenvolvimento da autonomia, pois permite ao futuro professor o exercício de criar e não somente ficar refém do pensamento único daqueles que o orientam. O formador esclareceu que o conjunto de suas intervenções teve como objetivo "libertá-los para que eles consigam ser livres e criar as suas próprias defesas". $\mathrm{Na}$ sua opinião, a formação para a autonomia acontece quando se exerce essa autonomia, o que pressupõe o desenvolvimento de um pensamento crítico.

Peço aos estagiários para que eles façam a sua crítica e a análise da aula. Noutro dia, houve um que muito agressivamente foi dizer que a aula foi muito má, que nunca tinha dado uma aula assim. E eu aí, como eu acho que as coisas não são gratuitas, obriguei-o diante dos colegas a dizer como daria esta aula, porque eu acho que eles ficam com aquela noção superficial de que eu posso dizer o que eu quiser. Quer dizer, eu não concordo nada com esta aula, eu não dava dessa maneira, mas não disse como é que dava. Depois, ele teve a infelicidade de que o discurso que ele usou era mais precário, porque a crítica era que a aula tinha se centrado muito no professor. Então, tinha esse problema: se centrado mais no professor do que no aluno. Desculpe-me, mas a aula deve ser centrada no professor, porque é o professor quem dirige a aula. Desculpe lá, isso é contra as novas teorias, mas aqui a estória da autoridade é o professor quem tem que dirigir a aula, o professor está ali. O que pode se dizer é assim: ele pode ouvir mais ou menos os alunos. (...) Por isso, a minha aula é sempre centrada no professor. Agora, o professor pode ser mais ou menos expositivo, mais ou menos diretivo, pode ser muitas coisas, mas é o professor quem tem que gerir a sala de aula. Eai é evidente que o pobre do rapaz foi infeliz. (...) A seguir os ouço, mas eles têm terror à crítica. Isso também é muito dos portugueses. Depois, a seguir, intervenho eu. Às vezes, eu intervenho antes, como foi o caso. Eu intervenho logo porque fico tão nervosa com as atitudes das pessoas que eu não consigo deixar naquele momento de dar a minha ferroadita ou de chamar a atenção. Você está sendo inconveniente, o seu discurso está a mostrar isso. (...) faço a crítica da aula. A minha crítica da aula se baseia em dois parâmetros: do ponto de vista didático e do ponto de vista científico. (S.Pt)

As situações apresentadas pelos formadores brasileiros e portugueses demonstram a relevância e o significado dos Estágios no desenvolvimento profissional dos futuros professores. A sintonia dos discursos está explícita na valorização da prática, na realização de seminários e sessões de natureza científica e pedagógico-didática, na articulação entre as disciplinas sobre ensino de Química e as escolas, com vista a uma prática pedagógica mais crítica e inovadora.

Um dos desdobramentos desta investigação foi identificar a concepção de Estágio que subjaz à prática dos formadores. Os relatos "do que fazem" no campo de estágio revela que não é considerado uma parte prática em contraposição à teoria.

Os depoimentos dos formadores sugerem que os Estágios não se orientam por uma racionalidade técnico-instrumental. Em relação aos saberes/conhecimentos, pode-se inferir que são valorizados tanto os conhecimentos gerados por teorias como aqueles saberes produzidos nas situações de ensino pelos professores. Todavia "o saber do professor proporciona um ponto de partida para a reflexão crítica. Simplesmente, não pode dar-se por pronto ou sistematizado na teoria, nem tornar-se definitivo na prática" ${ }^{25}$ (p. 61) pois, na prática pedagógica, os saberes são relativos e mutáveis.

No campo de Estágio, são explorados, pelos formadores, outros aspectos e outras dimensões dos saberes necessários à prática educativa. A afetividade, por exemplo, mistura-se aos saberes trabalhados com o futuro professor, impregnando-os.

É preciso que saibamos que, sem certas qualidades ou virtudes como amorosidade, respeito aos outros, tolerância, humildade, gosto pela alegria, gosto pela vida, abertura ao novo, disponibilidade à mudança, persistência na luta, recusa aos fatalismos, identificação com a esperança, abertura à justiça, não é possível a prática pedagógico-progressista, que não se faz apenas com ciência e técnica. ${ }^{24}$ (p.136)

\section{CONSIDERAÇÕES FINAIS}

As instituições formadoras de professores, no Brasil e em Portugal, continuam enfrentando problemas, pois a estrutura dos processos formativos obedece a múltiplos determinantes, que configuram um labirinto de mecanismos institucionais, políticos, sociais e culturais que defendem seus saberes e interesses. Como, por exemplo, Portugal, que, hoje, vive a polêmica com o fim da atribuição de duas turmas aos licenciandos e a conseqüente não-retribuição monetária, que limitará a formação inicial dos professores pelas universidades. A argumentação para o corte da remuneração dos estagiários é baseada na necessidade de contensão de despesas por parte do governo português. Outro argumento que tem sido apontado é o fato de que não é possível alimentar as expectativas dos jovens no sentido de que vão ter um futuro imediato como professores, quando não há essa possibilidade.

Do contexto português, dentre muitas, uma das principais contribuições a reter, no momento atual, é o papel do professor do ensino básico, como um dos supervisores de Estágio.Do contexto brasileiro, é importante ressaltar, no grupo investigado, os avanços no sentido de superar a dicotomia teoria-prática nos processos formativos.

Da experiência brasileira, necessita-se instituir políticas públicas que melhor definam o papel atribuído às escolas, principalmente, aos professores do ensino básico na formação de futuros professores; no papel dos licenciandos nas escolas; organização do tempo e espaços mais adequados a uma lógica que propicie uma vivência maior das situações escolares. 
Seja, pois, qual for a dimensão das contribuições deste trabalho investigativo, esperamos que possa acrescentar uma mais-valia de ação e de intervenção transformadora nos contextos formativos ${ }^{26}$ (p.19), enaltecendo um desafio no sentido de que os Estágios se configurem como "decisivos tempos de metamorfose na formação docente em química". ${ }^{26}$

\section{AGRADECIMENTOS}

A PICD/CAPES, à PDEE/CAPES pelo apoio financeiro e pelas bolsas concedidas.

\section{REFERÊNCIAS}

1. Pereira, J.; Educação e Sociedade 1999, p. 68.

2. Alarcão, I. Em Percursos de formação e desenvolvimento profissional; Sá-Chaves, I., ed.; Porto Editora: Porto, 1997, cap.1.

3. Giovanni, L. M. Em Aprendendo a ensinar: o caminho nada suave da docência; Guarnieri, M. R., org.; Campinas: Autores Associados, Araraquara: Programa de Pós-Graduação em Educação Escolar da Faculdade de Ciências e letras da UNESP, 2000, cap. 1.

4. Nóvoa, A. Em Vidas de professores; Nóvoa, A.,org.; Porto Editora: Porto, 1992, cap.1.

5. Marques, M. O.; A aprendizagem na mediação social do aprendido e da docência, Ed. UNIJUÍ: Ijuí, 1995.

6. Schön, D.; The reflective practitioner, Basic Books: New York, 1983.

7. Pérez-Gómez, A. Em Os professores e sua formação; Nóvoa, A., org.; Publicações Dom Quixote: Lisboa, 1992, cap.5.

8. Schnetzler, R. P.; Anais do IX ENDIPE, Águas de Lindóia, Brasil, 1998.

9. Schnetzler, R. P. Em Ensino de Ciências: fundamentos e abordagens; Schnetzler, R. P.; Aragão, R. M. R.,orgs.; Ed. Vieira: Campinas, 2000.

10. Pérez, M. F.; La profesionalización del docente, Escuela española: Madrid, 1988
11. Maldaner, O. A.; A formação inicial e continuada de professores de Química: professores pesquisadores, Ed. UNIJUÍ: Ijuí, 2000.

12. Schnetzler, R. P.; Atas do II Encontro Regional de Ensino de Ciências, Piracicaba, Brasil,1996.

13. Nóvoa, A. Em Os professores e a sua formação; Nóvoa, A., coord.; Publicações Dom Quixote: Lisboa, 1995, cap.1.

14. Zeichner, K. M.; A formação reflexiva de professores: idéias e práticas, EDUCA: Lisboa, 1993.

15. Zeichner, K. M. E.; Liston, D. P.; Reflective Teaching, Lawrence Erlbaum Associates: New York, 1996.

16. Bogdan, R. C.; Biklen, S. K.; Investigação qualitativa em educação, Porto Editora: Porto, 1994.

17. Queiroz, M. I. P. de.; Variações sobre a técnica de gravador no registro da informação viva, T. A. Queiroz: São Paulo, 1991.

18. Olabuenaga, J. R.; Ispizua, M. A.; La descodificacion de la vida cotidiana: metodos de investigacion cualitativa, Universidad de Deusto: Bilbao, 1989.

19. Caires, S.; Tese de Doutorado, Universidade do Minho, Portugal, 2003.

20. Gickman, C. D.; Gordon, S. P.; Ross-Gordon, J. M.; Supervision of instruction: A developmental approach, Ally \& Bacon: Massachusetts, 1998.

21. Mcnally, J.; Cope, P.; Inglis, B.; Stronach, I.; Teaching and teacher Education 1997, 13, 5.

22. Sanches, M. F. C.; Petrucci, R.; Revista da Educação 2002, XI, 1.

23. Goulart, S. M.; Revista Universidade Rural 2002, 24, 2.

24. Freire, P.; Pedagogia da autonomia: Saberes necessários à prática educativa, Paz e Terra: São Paulo, 1998.

25. Carr, W.; Kemmis, S.; Teoria crítica de la enseñanza: la investigaciónacción en la formación del profesorado, Martínez Roca: Barcelona, 1988.

26. Sá-Chaves, I.; Formação, Conhecimento e Supervisão: contributos na área da formação de professores e de outros profissionais, Universidade de Aveiro: Aveiro, 2000. 